\title{
Review Article \\ Current Development of Silver Nanoparticle Preparation, Investigation, and Application in the Field of Medicine
}

\author{
Maxwell Murphy, ${ }^{1}$ Kang Ting, ${ }^{1,2}$ Xinli Zhang, ${ }^{1}$ Chia Soo, ${ }^{3}$ and Zhong Zheng ${ }^{1,3}$ \\ ${ }^{1}$ Dental and Craniofacial Research Institute and Division of Growth and Development, Section of Orthodontics, \\ School of Dentistry, University of California, Los Angeles, CA 90095-1759, USA \\ ${ }^{2}$ California NanoSystems Institute, University of California, Los Angeles, CA 90095, USA \\ ${ }^{3}$ UCLA Department of Surgery and Department of Orthopaedic Surgery and the Orthopaedic Hospital Research Center, \\ University of California, Los Angeles, CA 90095-1759, USA \\ Correspondence should be addressed to Chia Soo; scarlesslabs@earthlink.net and Zhong Zheng; zzheng@dentistry.ucla.edu
}

Received 15 September 2014; Accepted 14 October 2014

Academic Editor: Xiaoming Li

Copyright (C) 2015 Maxwell Murphy et al. This is an open access article distributed under the Creative Commons Attribution License, which permits unrestricted use, distribution, and reproduction in any medium, provided the original work is properly cited.

\begin{abstract}
The invited review covers different research areas of silver nanoparticles (AgNPs), including the synthesis strategies of AgNPs, antimicrobial and anti-inflammatory properties of AgNPs, osteoconductive and osteoinductive activities of AgNP-based materials, and potential toxicity of AgNPs. The potential mechanisms of AgNP's biological efficacy as well as its potential toxicity are discussed as well. In addition, the current development of AgNP applications, especially in the area of therapeutics, is also summarized.
\end{abstract}

\section{Introduction}

Silver has been used as an antimicrobial agent for centuries. For example, the Phoenicians used silver vessels to preserve water and wine during their long voyages [1]. In addition, ancient Egyptians believed that silver powder provided beneficial healing and antidisease properties; thus silver compounds were used for prohibiting wound infection prior to antibiotics [1]. In 1884, German obstetrician Crede introduced $1 \%$ silver nitrate $\left(\mathrm{AgNO}_{3}\right)$ as an eye solution for prevention of gonococcal ophthalmia neonatorum, which is most likely the first scientifically documented medical use of silver [1]. In modern society, topically used silver sulfadiazine cream is the standard antibacterial treatment for serious burn wounds and is still widely used in burn units today [2]. However, inadequate local retention and severe cytotoxic effects limited the clinical use of these ionic reservoir forms of silver materials [3-5].

Due to recent advances in nanotechnology, it is now possible to produce silver at the nanoscale $[6,7]$. In addition to their potential electronic and transparent conductor applications, the emergence of nanosilver materials in antimicrobial consumer goods and medical products is driving the growth of the nanosilver market, which is expected to grow in value from US $\$ 290$ million in 2011 to around US $\$ 1.2$ billion by 2016 (http://www.merid.org/Content/News_Services/Nanotechnology_and_Development_News/Articles/2011/ Sep/14/nanosilver.aspx). Among the different nanosilver preparations, silver nanoparticles (AgNPs) are made up of $20-15,000$ silver atoms, generally range from 1 to $100 \mathrm{~nm}$ in diameter and present in one dimension [8]. These extremely small dimensions lead to a high surface area to volume ratio and, subsequently, change the physical, chemical, and biological properties of AgNPs $[9,10]$. This review critically outlines recent developments in the synthesis, physicochemical properties, toxicity, and biomedical applications of AgNPs.

\section{Synthesis of AgNPs}

AgNPs can be synthesized in a variety of different ways, each with its own advantages and disadvantages. Till now, the most common methods of AgNPs synthesis are through chemical reduction of silver salt (e.g., $\mathrm{AgNO}_{3}$ ) using a reducing agent (e.g., sodium borohydride) [11]. During chemical reduction, silver ion $\left(\mathrm{Ag}^{+}\right)$receives an electron from the reducing 
agent and reverts to its metallic form $\left(\mathrm{Ag}^{0}\right)$ eventually clustering to form AgNPs. $\mathrm{AgNO}_{3}$ is the most often used silver salt for these chemical methods of AgNP synthesis due to its low cost and high stability [10]. Generally, a capping agent [e.g., poly(N-vinyl-2pyrrolidone) (PVP)] is used during chemical reduction to stabilize the nanoparticles and prevent them from aggregating [11]. However, reducing agents and organic solvents used in chemical reduction, such as $N, N$ dimethylformamide, hydration hydrazine, and sodium borohydride, are highly reactive and pose potential environmental and biological risks [12]. Moreover, the inability to control the size of the AgNPs obtained by chemical reduction could result in a wide distribution of sizes of AgNPs obtained.

Photoreduction of silver salt in the presence of PVP or citrate by ultraviolet (UV) light is another simple and effective strategy to produce AgNPs [11, 13, 14]. However, most photoreduction methods still use organic solvents, such as PVP, and are unable to control the size of obtained AgNPs $[11,13,14]$.

Recent efforts have been focused on developing new green chemistry methods of AgNPs synthesis with the advantage of using natural products and avoiding toxic reducing agents, organic solvents, and wasteful purifications with high cytotoxic residuals. With these methods, molecules produced by living organisms such as bacteria, fungi, or plants replace the reducing and capping agents [15-18]. For example, $\mathrm{AgNO}_{3}$ is added to chitosan obtained from various species of bacteria and dissolved in acetic acid. The silver ions are then reduced through gamma radiation and stabilized by chitosan [19, 20]. There have also been efforts to synthesize AgNPs in the lamellar space of montmorillonite/chitosan by utilizing the UV irradiation reduction method in the absence of any reducing agent or heat treatment [21]. Additionally, AgNPs have been synthesized via photoreduction of $\mathrm{AgNO}_{3}$ in layered inorganic clay suspensions, laponite, which serve as stabilizing agents that prevent nanoparticles from aggregating instead of using PVP [22]. The disadvantage to using these types of green synthesis is the potential of contamination due to the pathogenic bacteria created during the purification [10]. Consequently, herbal extracts and essential oils are gaining in popularity for methods of green synthesis due to their antioxidant and antimicrobial properties while avoiding the use of pathogenic bacteria [23-25]. However, the disadvantage of using herbal extracts is once again the wide distribution of particle sizes obtained.

In addition, there have also been novel developments by using green physical methods for AgNP synthesis avoiding the use of chemicals completely. One such method, laser ablation, can synthesize pure colloidal AgNPs in solutions without the use of chemical reagents $[27,28]$. However, the concentration and morphology of these AgNPs are inconsistent since they are dependent on many parameters such as number of laser shots, wavelength of the laser, laser fluence, liquid medium, and ablation time duration $[27,28]$. Another chemical-free method for AgNP synthesis involves the application of an electrical current between two silver wires in deionized water causing surface silver atoms to evaporate and condense back into aqueous AgNPs [29]. Without the use of chemicals, there are no toxic residuals or contaminations. However, since no capping agents are used, agglomeration of AgNPs may pose a problem [30]. To date, perhaps the most effective method for AgNP synthesis is the production through a novel, nonchemically based proprietary process (USPTO $7,282,167)$. In this process, silver granules with a purity of 99.99\% are distilled into silver vapor by heating on a ceramic conductive element. By controlling the generation rate of silver vapor, gas flow, and reactor pressure, the nucleation rate of silver nanoclusters can be designed to produce nanosilver liquid droplets, which are then condensed in a stream of flowing helium gas into solid crystalline spherical AgNPs of desired size. The hot nanoparticles are then attracted to a cooled chamber wall by thermophoresis where they are mechanically collected and packaged for use. Furthermore, the active surface of the obtained highly purified ( $>99.9 \%$ pure) $20-40 \mathrm{~nm}$ AgNPs $\left(15-25 \mathrm{~m}^{2} / \mathrm{g}\right)$ is much greater compared to commercial nonnanoscale silver powder $\left(1-2 \mathrm{~m}^{2} / \mathrm{g}\right)$ and previously reported AgNPs $\left(4 \mathrm{~m}^{2} / \mathrm{g}\right)[31,32]$.

\section{Biological Properties of AgNPs}

Currently, the unique antimicrobial properties of AgNPs have led to their application in areas such as clothing manufacturing, food preservation, and water purification [33-36]. More importantly, AgNPs are being increasingly utilized in the medical industry due to their antibacterial, antifungal, antiviral, anti-inflammatory, and osteoinductive effects as well as their ability to enhance wound healing [32, 37-42].

3.1. Antibacterial Properties of AgNPs. Antibiotics are standard antimicrobials used in medicine that bind to specific chemical targets of bacteria not present in humans [41]. However, this binding specificity narrows the number of bacterial species that are vulnerable to a specific antibiotic and contributes to the antibiotic resistance developed by bacteria, ultimately creating multidrug resistant bacteria [43]. With the increasing number of infections due to multidrug resistant bacteria, there has been a need for effective antimicrobial alternatives. Thus, silver is a great alternative because it is an antiseptic that targets a broad spectrum of $\mathrm{Gram}^{+}$and $\mathrm{Gram}^{-}$ bacteria as well as vancomycin-resistant strains $[7,31,36,40$, 43]. Moreover, silver-resistant bacteria are rarely observed in hospital microbial germ flora because silver resistance requires one generation of bacteria to undergo three separate mutations in three different bacterial systems [31, 44].

Mechanistically, silver-based materials are thought to release silver ions $\left(\mathrm{Ag}^{+}\right)$in aqueous solution, which account for their antibacterial properties by attaching to specific thiol $(-\mathrm{SH})$ groups containing sulfur and hydrogen found in a variety of structural and functional bacterial proteins [4547]. It should be noted that the reservoir form of the active silver ions might differ [43]. For instance, the reservoir form of $\mathrm{AgNO}_{3}$ is a chemical combination of $\mathrm{Ag}(\mathrm{I})$ and nitrate, but $\mathrm{AgNO}_{3}$ is not suitable for sustained local application due to its high solubility as an ionic salt. Nonnanoscale elemental silver $[\operatorname{Ag}(0)]$ used in silverware and jewelry is relatively insoluble in most fluids, resulting in minimal oxidative $\mathrm{Ag}^{+}$ release [43]. Thus, neither the in vitro antibacterial action nor the clinical behavior of nonnanoscale silver-coated stainless 
steel cortical screws significantly differed from that of the uncoated ones [48]. Due to the greater surface-to-mass ratio, AgNPs offer greater active surface, higher solubility, and chemical reactivity. As a result, although the reservoir form for AgNPs is also elemental silver $[\mathrm{Ag}(0)]$, AgNPs have higher release of oxidative $\mathrm{Ag}^{+}$and/or partially oxidized AgNP with chemisorbed (surface-bound) $\mathrm{Ag}(\mathrm{I})$ and thus have higher antibacterial activity compared with conventional silver reparations $[40,49,50]$.

However, a comparative study of AgNPs, $\mathrm{AgNO}_{3}$, and silver chloride $(\mathrm{AgCl})$ found that AgNPs have higher antibacterial properties than free silver ions $\left(\mathrm{Ag}^{+}\right)$[51]. This implies that AgNPs have intrinsic antibacterial properties not dependent on the release of silver ions $\left(\mathrm{Ag}^{+}\right)$. One possible mechanism of $\mathrm{Ag}^{+}$releasing-independent bactericidal effects of AgNPs is partly due to the ability of AgNPs to attach to the bacterial cell wall and penetrate it, thereby increasing its permeability and, ultimately, leading to cell death [52]. Another possible mechanism attempts to explain the antibacterial effect of positively charged silver atoms $\left(\mathrm{Ag}^{+}\right)$on the surface of AgNPs through the formation of free radicals and the subsequent free radical-induced membrane damage [53]. Furthermore, a recent study suggests a novel mechanism for the antibacterial effect of AgNPs, namely, the induction of a bacterial apoptosis-like response [54]. This new proposed mechanism involves an accumulation of reactive oxygen species (ROS), increased intracellular calcium levels, and phosphatidylserine exposure in the outer membrane, all hallmarks of early apoptosis. It also includes disruption of the membrane potential and DNA degradation, indicators of late apoptosis, in bacterial cells treated with AgNPs [54]. Collectively, it is believed that AgNPs are thought to interact with the bacterial DNA, the peptidoglycan cell wall and plasma membrane, and the bacterial proteins involved with the electron transport chain to produce their bactericidal effects [30, 47, 55-57]. Although it is not fully understood which mechanism provides the main antibacterial effect, a combined effect of each mechanism provides broadspectrum antibacterial resistance.

It is worth noting that the size and shape of nanosilver influence its antibacterial efficacy. Previous studies have demonstrated that 5-50 $\mathrm{nm}$ sized AgNPs are bactericidal [31]. Further investigation suggested that the greater the surface area of AgNPs is, the greater the antibacterial activity is [5860]. In addition, Sadeghi et al. reported that nanoscale silver plates demonstrated the best antimicrobial activity against Staphylococcus aureus and Escherichia coli compared with nanosca le silver rods and particles [61]. Antibacterial activity of nanosilver was found to be dependent on the surface area of nanosilver shapes with nanoscale silver plates showing the greatest surface area [61]. Thus, nanosilver with the greatest surface area exhibits better antibacterial properties at lower concentrations [61].

As discussed, the evidence supporting AgNPs as an effective antimicrobial agent is abundant with AgNPs showing broad-spectrum resistance to bacterial strains such as $S$. aureus (including methicillin resistant strains, known as MRSA), Staphylococcus epidermidis (including methicillin resistant strains, known as MRSE), Enterococcus faecalis,
Enterococcus faecium, E. coli, Pseudomonas aeruginosa, and Klebsiella pneumonia and even vancomycin-resistant strains $[7,31,32,36,40,42,43]$.

3.2. Antifungal Properties of AgNPs. Long-term, repetitive administration of standard antifungal drugs leads to increased fungal resistance, especially by the Candida species [39]. Therefore, new antifungal agents are constantly being investigated. AgNPs have displayed many antifungal properties against common fungi and thus offer potential as an effective antifungal agent. A recent study found that a AgNP-coated reverse osmosis membrane, which is used in water purification systems, exhibited good antifungal activities against fungal strains such as Candida tropicalis, Candida krusei, Candida glabrata, and Candida albicans [36]. Additionally, Pulit et al. reported that AgNP suspensions created from aqueous raspberry extract acted as effective growth inhibition factors against two resistant fungal strains Cladosporium cladosporioides and Aspergillus niger [39]. Furthermore, a higher concentration of AgNPs induced stronger reduction of fungal growth in both cases. With the promising potential of AgNPs as a broad-spectrum antifungal agent, further investigation is warranted to elucidate the mechanisms concerning their antifungal properties.

3.3. Antiviral Properties of AgNPs. Various viruses, such as influenza, hepatitis, herpes simplex virus (HSV), and human immunodeficiency virus (HIV), can be life threatening [62]. Although many vaccines have been developed against various viruses, medicine has yet to develop a broad-spectrum antiviral vaccine. Furthermore, these viruses are developing antiviral resistance to current treatments and classical antiviral drugs, especially in immunocompromised patients [62]. In light of this, there is a pressing need for the development of new antiviral agents against a broad spectrum of viruses. AgNPs act as a broad-spectrum agent against a variety of viral strains and are not prone to developing resistance [10]. For example, studies have demonstrated antiviral activity of AgNPs against HSV-1, HSV-2, hepatitis B, and human immunodeficiency virus 1 (HIV-1) [63-66]. With regard to HSV-1, AgNPs are hypothesized to target the virus and to compete for its binding to cellular heparin sulfate through their sulfonate end groups, leading to the blockage of viral entry into the cell and the prevention of subsequent infection [63]. Additionally, a recent study demonstrated that $100 \mu \mathrm{g} / \mathrm{mL}$ of AgNPs could completely inhibit HSV2 replication [66]. AgNPs at nontoxic concentrations were capable of inhibiting HSV-2 replication when administered prior to viral infection or soon after initial virus exposure. These findings suggest that the mode of action of AgNPs occurs during the early phases of viral replication [66]. Furthermore, there has been evidence of AgNP's antiviral activity against HIV-1 at noncytotoxic concentrations. AgNPs exerted anti-HIV activity at an early stage of viral replication, most likely as a virucidal agent or as an inhibitor of viral entry [65].

3.4. Anti-Inflammatory Properties of AgNPs. Despite the billions of dollars that have been spent on immunological 
research, few effective anti-inflammatory drugs have emerged [72]. Thus, an urgent need for new drugs exists, as many inflammatory diseases are insufficiently responsive to current medications [72]. Recently, there has been increasing evidence that AgNPs are viable anti-inflammatory agents. Initially, anti-inflammatory properties of AgNPs were investigated by applying AgNP-coated, 0.5\% silver nitrate $\left(\mathrm{AgNO}_{3}\right)$, or saline wound dressings to a porcine model of contact dermatitis [37]. AgNP-coated wound dressings outperformed other wound dressings as erythema, edema, and histological data showed that AgNP-treated pigs had near-normal skin after 72 hours, while other treatment groups remained inflamed [37]. Furthermore, AgNP-coated wound dressings decreased levels of proinflammatory cytokines transforming growth factor- (TGF-) $\beta$ and tumor necrosis factor- (TNF-) $\alpha$ compared with other treatment groups. Similarly, another study evaluating the antiinflammatory effects of AgNPs on an allergic rhinitis mouse model reported reduced nasal symptoms in sensitized mice and an inhibition of ovalbumin-specific immunoglobulin E, interleukin- (IL-) 4, and IL-10 [73]. Moreover, decreased inflammatory cell infiltration and goblet cell hyperplasia were also observed [73]. Further evidence of the antiinflammatory effects of AgNPs has been demonstrated in a postoperative peritoneal adhesion model and through the use of AgNP-coated sutures [74, 75]. Wong et al. found that AgNPs are effective at decreasing inflammation in peritoneal adhesions without significant cytotoxic effects while Zhang et al. reported that using AgNP-coated sutures decreased inflammation and improved mechanical strength at intestinal anastomosis in mice [74, 75]. Our previous studies have also demonstrated that AgNP/poly(lactic-coglycolic acid) (PLGA-) coated stainless steel alloy (SNPSA) materials significantly reduced bacterial infection and inflammatory cell infiltration in the intramedullary tissue in rat femoral canals (Figure 1) [76]. Mechanistically, the antiinflammatory effects of AgNPs are not fully understood but are thought to be associated with the TNF- $\alpha$ pathway [74].

3.5. Osteoconductivity and Osteoinductivity of AgNP-Based Materials. Previously, by implanting AgNP/PLGA composite grafts for the healing of infected bone defects into grossly infected critical-sized bone segmental defects, we demonstrated that AgNP/PLGA composite grafts possess significant, antibacterial properties and osteoconductivity in vivo (Figure 2) [32]. AgNP/PLGA composite grafts displayed osteoconductive properties as they did not inhibit adherence, proliferation, alkaline phosphatase activity, or mineralization of ongrowth MC3T3-E1 preosteoblasts in vivo [32]. In a follow-up experiment, we unexpectedly found that SNPSA materials not only exhibited strong antibacterial activity in vitro and ex vivo, but also promoted MC3T3-E1 preosteoblast proliferation and maturation in vitro [42]. Furthermore, SNPSA implants induced osteogenesis while suppressing bacterial survival in contaminated rat femoral canals with no observed cytotoxicity (Figure 1) [42]. These findings require more research into the osteoconductive and osteoinductive properties of AgNP-based materials, but they offer promising therapeutic material for orthopedic surgery.

\section{Toxicity of AgNPs}

Applying silver as an antimicrobial agent has been hindered by its potential toxic effects, such as argyria, an irreversible pigmentation of the skin and eyes due to inappropriate silver deposition [3]. Thus, the toxicity of AgNPs must be investigated for commercial products and before widespread medical application. Also, environmental pollution must be considered to avoid ecological damage.

AgNPs enter the human body most often through the respiratory tract, gastrointestinal tract, skin, and female genital tract, as well as through systemic administration [77]. Recently, an in vivo oral toxicity study of AgNPs on Sprague-Dawley (SD) rats demonstrated the accumulation of AgNPs in the blood, liver, lungs, kidneys, stomach, testes, and brain, but showed no significant genotoxicity function after oral administration of AgNPs of $60 \mathrm{~nm}$ average size for 28 days at different doses [78]. Similarly, another in vivo 28dayinhalation toxicity study of $1.98-64.9 \mathrm{~nm}$ AgNPs on SD rats found no effects on respiratory function, hematology, or blood biochemical values [79]. In our previous studies, $3 \mathrm{D}$ porous graft and $43 \mu \mathrm{m}$ thick PLGA coating composited by up to 2\% 20-40 nm AgNPs and PLGA materials did not show significant cytotoxicity against preosteoblast MC3T3$\mathrm{Cl}$ cells in vitro or toxicity during 8-week bone regeneration in $\mathrm{SD}$ rats in vivo $[32,42]$. Other studies have shown that 20-25 nm AgNPs effectively inhibit microorganisms without causing significant cytotoxicity and that $10-20 \mathrm{~nm}$ AgNPs are nontoxic in mice and guinea pigs when administered by the oral, ocular, and dermal routes [32, 80]. In contrast, a 90day whole body inhalation toxicity study of $18 \mathrm{~nm}$ AgNPs on SD rats reported that prolonged exposure to AgNPs elicited an inflammatory response within the alveoli and induced alterations in lung function at all particle concentrations [81]. Also, AgNPs have been reported to cross the blood-brain barrier in rats and induce neuronal degeneration and necrosis through accumulation in the brain over a long period of time [82]. Additionally, Vandebriel et al. and de Jong et al. found that intravenous administration of both 20 and $100 \mathrm{~nm}$ AgNPs in a 28-day repeated-dose toxicity study in SD rats induces suppression of the functional immune system [83, 84]. In the area of development, a study reported that AgNPs less than $12 \mathrm{~nm}$ in size affected early development of fish embryos, caused chromosomal aberrations and DNA damage, and induced proliferation arrest in cell lines of zebrafish indicating that AgNPs must be investigated for their potential teratogenic effects in humans [85]. In vitro studies have demonstrated that AgNPs are cytotoxic to various types of cells including neuroendocrine cells, mouse germ line cells, mouse fibroblasts, rat liver cells, human alveolar epithelial cell line, human peripheral blood mononuclear cells, normal human lung fibroblast cells, and human glioblastoma cells [86-91]. These conflicting results reveal the difficulty of pinpointing the overall toxicity of AgNPs to humans because the tremendous variation in particle size, particle aggregation, and concentration or coating thickness (in implants) of AgNPs has different profiles of silver release and bioactivity [43]. In short, much longer and detailed studies must be carried out to seriously consider AgNPs' potential toxicity in humans. 

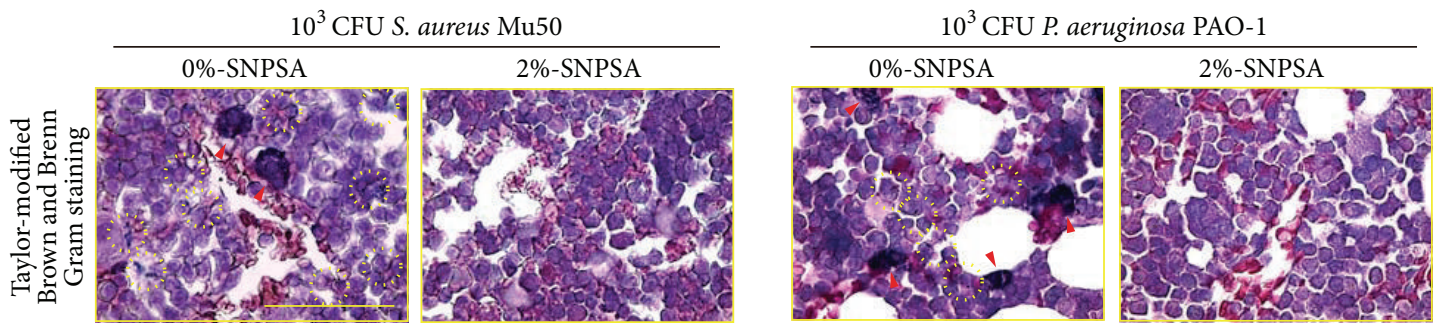

(a)
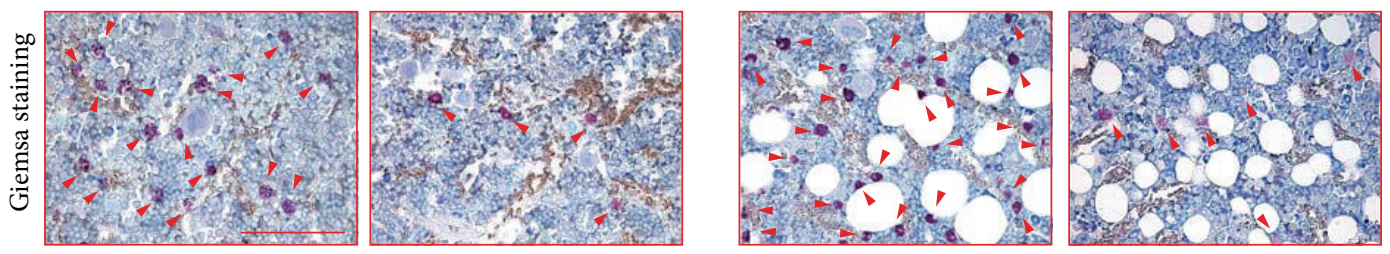

(b)
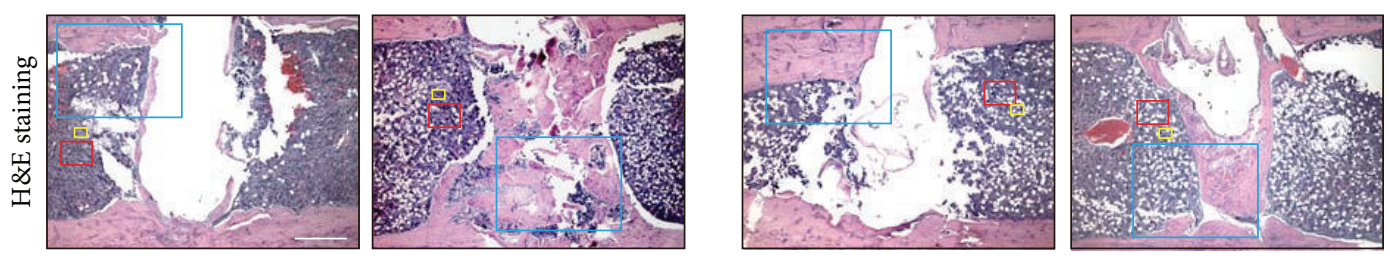

(c)
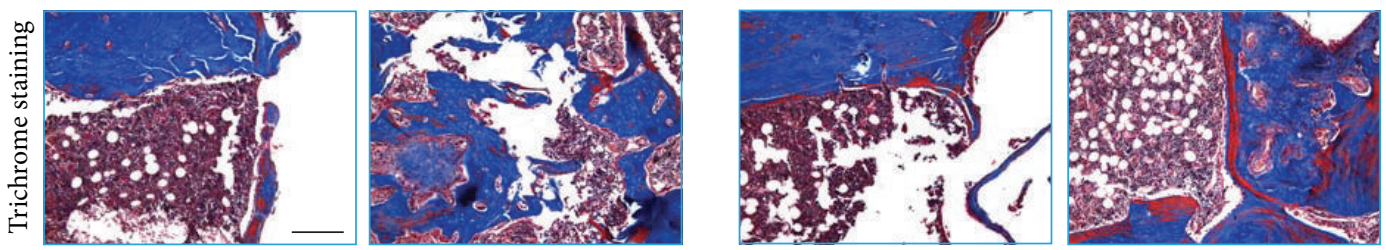

(d)
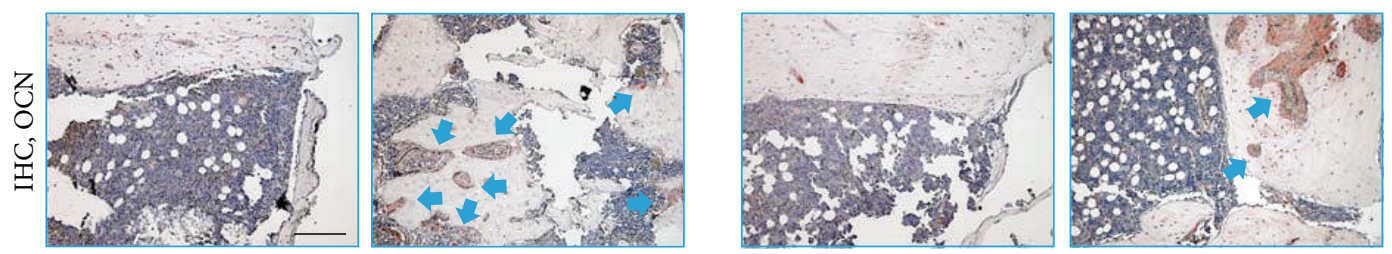

(e)

FIGURE 1: Histological and immunohistochemical staining of contaminated $0 \%$ and 2\% AgNP/PLGA-coated 316L stainless steel alloy (SNPSA) implants in rat femoral canals (FCs) at 8 weeks after implantation. $10^{3}$ colony forming units (CFU) S. aureus Mu50 or P. aeruginosa PAO-1 in $10 \mu \mathrm{L}$ phosphate buffered saline (PBS) $\left(10^{5} \mathrm{CFU} / \mathrm{mL}\right.$, the typical criteria for invasive tissue infection [26]) were pipetted into the canal before implantation for bacterial invasion. Taylor-modified Brown and Brenn Gram staining (a) and Giemsa staining (b) revealed bacterial persistence (yellow dotted circles) with massive inflammatory cell infiltration (red arrowheads) in the intramedullary tissue around 0\% SNPSA implants in rat FCs. In contrast, no bacterial survival was evident around 2\% SNPSA implants in the same situation, and inflammatory cell infiltration in the intramedullary tissues around the implants was minimal. Moreover, only minimal bone formation around the $0 \%$ SNPSA groups was observed, whereas significant bone formation (blue arrows) was detected around 2\% SNPSA implants, as shown by hematoxylin and eosin (H\&E) staining (c), Masson's trichrome staining (d), and immunohistochemical staining of high-intensity osteocalcin signals (e). Yellow scale bar $=50 \mu \mathrm{m}$; red scale bar $=100 \mu \mathrm{m}$; white scale bar $=500 \mu \mathrm{m}$; black scale bar $=200 \mu \mathrm{m}$. Reprinted from Biomaterials, Vol. 33, Y. Liu and Z. Zheng et al., "The antimicrobial and osteoinductive properties of silver nanoparticle/poly (DL-lactic-co-glycolic acid)-coated stainless steel," pp. 8745-8756, 2012, with permission from Elsevier.

A potential contributing factor to AgNPs cytotoxicity is the oxidative stress caused by the creation of reactive oxygen species after AgNPs enter the cell [89]. AgNPs also damage cellular components leading to DNA damage, activation of antioxidant enzymes, depletion of antioxidant molecules (e.g., glutathione), binding and disabling of proteins, and damage to the cell membrane [92]. However, an emerging study suggests that cellular oxidative stress may not be the main cause of toxicity and that it might be a different mechanism all together. Two widely used in vitro human cell lines 

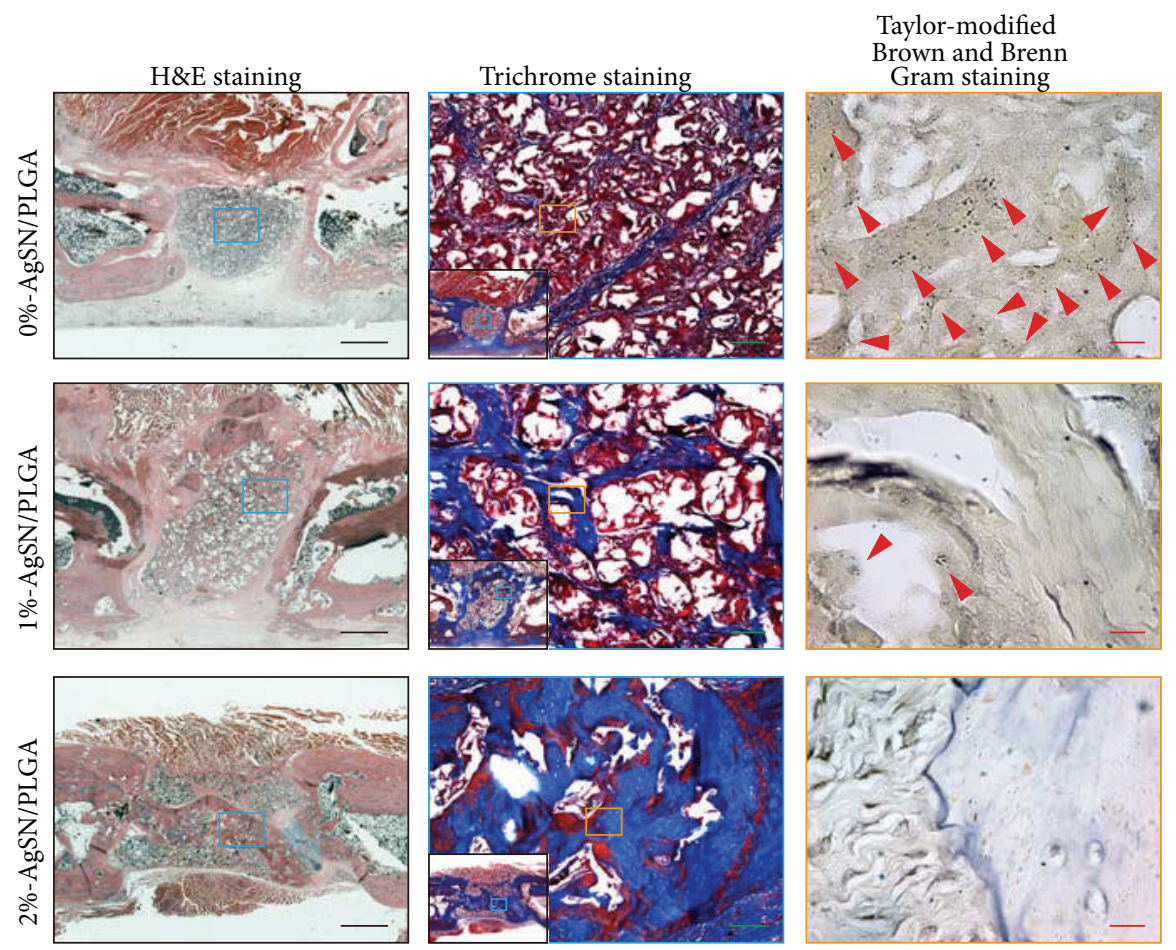

(a)

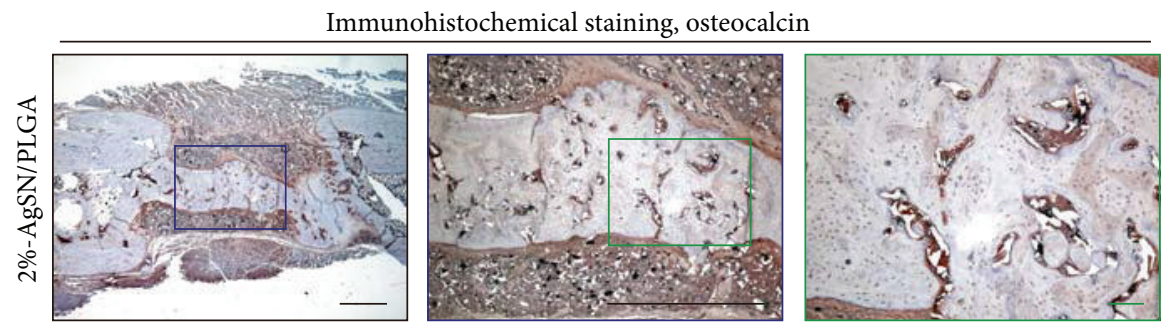

(b)

FIGURE 2: Histological and immunohistochemical staining of contaminated rat femoral segmental (FSD) defects implanted with $0.0 \%, 1.0 \%$, and $2.0 \% \mathrm{AgNP} / \mathrm{PLGA}$ bone grafts coupled with $30 \mu \mathrm{g} / \mathrm{mL}$ bone morphogenetic protein 2 (BMP-2) at 12 weeks after implantation. With a small oscillating saw blade, a $6 \mathrm{~mm}$ critical-sized middiaphyseal defect was created in 16-18-week-old male SD rat femur. The volume of the defect was approximately $75 \mu \mathrm{L} .10^{8}$ CFU S. aureus Mu50 in $75 \mu \mathrm{L} \mathrm{20 \%} \mathrm{gelatin} \mathrm{gel} \mathrm{was} \mathrm{implanted} \mathrm{into} \mathrm{the} \mathrm{defect} \mathrm{before} \mathrm{implantation.} \mathrm{H \& E} \mathrm{staining}$ and Masson's trichrome staining (a) revealed no bone regeneration in BMP-2/0.0\% AgNP/PLGA (control BMP-2 coupled control PLGA) implanted groups with obvious continued bacterial contamination evidenced by Taylor modified Brown and Brenn Gram stain (red arrows). However, BMP-2/2.0\% NS/PLGA grafts promoted significantly greater bone formation to form a mineralized bony bridge between the two defect ends by eliminating bacteria in the defect area (a). Immunohistochemical staining against osteocalcin showed active bone regeneration around the mineralized bridge and in the marrow-like cavities in the bridge (b). Black scale bar $=2 \mathrm{~mm}$; green scale bar $=100 \mu \mathrm{m}$; red scale bar $=10 \mu \mathrm{m}$. Reprinted from Biomaterials, Vol. 31, Z. Zheng et al. “The use of BMP-2 coupled-nanosilver-PLGA composite grafts to induce bone repair in grossly infected segmental defects," pp. 9293-9300, 2010, with permission from Elsevier.

for determining cytotoxicity in the liver and gastrointestinal tract, hepatoblastoma HepG2 and colon carcinoma Caco2, did not display any AgNP-induced oxidative stress when exposed to AgNPs at a concentration of $1-20 \mu \mathrm{g} / \mathrm{mL}$ [93]. These results suggest that cellular oxidative stress did not play a major role in the observed cytotoxicity of AgNPs in HepG2 and Caco2 cells and that a different mechanism of AgNP-induced mitochondrial injury leads to the cytotoxicity. The HepG2 and Caco2 cells appear to be targets for AgNPs, suggesting that the differences in the mechanisms of toxicity induced by AgNP may be largely a consequence of the type of cells used [93]. Another study reported a correlation between AgNP size and inhibitory effects on mitochondria, with smaller AgNPs of $15 \mathrm{~nm}$ significantly more toxic than larger AgNPs of $55 \mathrm{~nm}$ [94]. Thus, oxidative stress, cell type, and preparation of AgNPs all play a role in the toxicity. With regard to the environment, a recent study found that AgNPs have a significant impact on the microbial community and severely disrupt the natural seasonal progression of tundra assemblages [95]. This effect was evidenced by levels of differential respiration in $0.066 \%$ AgNP-treated soil that were only half that of control soils, a decrease in signature 
TABLE 1: Commonly used burn topical antimicrobials.

\begin{tabular}{ll}
\hline Agent & Advantages \\
\hline & (i) Bactericidal against most gram positive, \\
& gram negatives, and yeast \\
& (ii) Avoids mucopurulent exudate formation \\
(pseudoeschar) & (iii) Minimal pain after application \\
Introduced in 1964 & (iv) No hypersensitivity
\end{tabular}

Disadvantages

(i) No eschar penetration

(ii) Electrolyte imbalance (hypotonic solution depletes wounds cations)

(iii) Needs frequent application

(iv) Discolors wound bed

(v) Possible methemoglobinemia

(vi) Rare silver toxicity

(i) Potential loss of bacteriostatic action at high $\left(>10^{6}\right)$ bacterial loads

Mafenide acetate-historically $11.1 \%$ in water-soluble cream, but newer formulation is $8.5 \%$ First introduced in 1964

(i) Bacteriostatic against most gram positives, gram negatives; may be more effective for clostridial and pseudomonal infections than silver nitrate or SSD

(ii) Good eschar penetration (ii) Effective concentration in eschar drops below therapeutic levels after 10 hours - needing twice daily application

(iii) Metabolic acidosis [drug and metabolite (p-carboxybenzenesulfonamide) inhibit carbonic anhydrase-can worsen ventilation]

(iv) Pain after application

(v) Potential hypersensitivity

(i) Less activity against certain gram negatives

(Enterobacter and Pseudomonas) and yeast

$1 \%$ silver sulfadiazine (SSD)

(i) Bactericidal against most gram positives and some gram negatives water-soluble cream

(ii) Minimal pain after application

(ii) Poor eschar penetration

(iii) Forms pseudoeschar that requires daily washings

(iv) Neutropenia ${ }^{\mathrm{A}}$

(v) Potential hypersensitivity to sulfa component

(vi) Rare silver toxicity

(i) Similar to cream

(ii) Effective concentration in eschar drops below

Mafenide acetate- $5 \%$ solution (i) Similar to cream

First introduced in $1971 \quad$ (ii) Less pain after application versus cream

Acticoat

Rayon/polyester core encased

in dense polyethylene mesh

coated with nanocrystalline

silver

(i) Bactericidal against most gram positives, gram negatives, and fungus

(ii) Sustained silver release for 3-7 days

(iii) Minimizes pain from daily dressings therapeutic levels after 6-8 hours-needing $3 \mathrm{x}-4 \mathrm{x}$ daily application

(i) Poor eschar penetration

(ii) Requires maintenance of moist dressings for silver release

(iii) Rare silver toxicity

Table information modified and compiled from the following references: [67-71].

${ }^{\text {A }}$ Neutropenia thought to be due to transient depression of granulocyte-macrophage progenitor cells in the marrow [67].

bacterial fatty acids, and changes in both richness and evenness in bacterial and fungal DNA sequence assemblages [95]. Similarly, Völker et al. investigated the effects of AgNPs on Potamopyrgus antipodarum, a freshwater mudsnail, and found that AgNPs decreased their reproduction [96]. Thus, further assessment of the environmental pollution and risks due to AgNP exposure is required to prevent damage to the environment.

\section{Applications of AgNPs}

AgNPs have been widely used as an antibacterial coat in medical applications such as wound dressings, cardiovascular implants, catheters, orthopedic implants, and dental composites.

5.1. Wound Dressings. Silver wound dressings have been used for over a decade to clinically treat various wounds, such as burns (Table 1), chronic ulcers, toxic epidermal necrolysis, and pemphigus [30]. Surprisingly, compared to standard silver sulfadiazine and gauze dressings, AgNP wound dressings significantly decreased wound healing time by an average of 3.35 days while simultaneously increasing bacterial clearance from infected wounds with no adverse effects [38]. Meanwhile, AgNP wound dressings could enhance healing in superficial burn wounds compared with conventional $1 \%$ silver sulfadiazine cream or plain petrolatum gauze [97]. However, AgNP wound dressings made no difference in the healing of deep burn wounds, compared with $1 \%$ silver sulfadiazine, suggesting that AgNPs accelerate reepithelialization but not new tissue formation, such as angiogenesis and proliferation [97].

As research in this area continues, new ideas for AgNP wound dressings with the intention of further increasing wound healing and antibacterial efficacy are being investigated. For example, a recent chitosan-AgNP wound dressing demonstrated significantly improved wound healing compared with $1 \%$ silver sulfadiazine along with the deposition of less silver, which may lower the occurrence of argyria or skin discoloration [98]. Additionally, chitin-AgNP wound dressings possessed a strong antibacterial potential for wound healing applications $[99,100]$. 
5.2. Cardiovascular Implants. In order to reduce the occurrence of endocarditis, a prosthetic silicone heart valve was the first cardiovascular device coated with silver element [101]. The use of silver was intended to prevent bacterial infection on the silicone valve thereby reducing the inflammation response of the heart. However, clinical trials testing the silver heart valve found that silver causes hypersensitivity, inhibits normal fibroblast function, and leads to paravalvular leakage in patients [101]. Thus, efforts turned towards incorporating AgNPs into medical devices as a potential for providing a safe, nontoxic antibacterial coating. The development of a new nanocomposite with AgNPs and diamond-like carbon as a surface coating for heart valves and stents demonstrated antithrombogenic and antibacterial properties [102]. Additionally, studies have also found that incorporation of nanostructured materials into the backbone of polymers in polymeric heart valves improves biocompatibility, resistance to calcification, and durability [103].

5.3. Catheters. Catheters used in the hospital setting have a high propensity for infection, which can lead to unwanted complications. Thus, AgNPs have been investigated as a method of reducing biofilm growth on catheters. Recently, polyurethane catheters have been modified with a coat of AgNPs to create effective antibacterial catheters [104]. Multiple studies have reported that AgNP-coated catheters can effectively reduce bacteria for up to 72 hours in animal models [105-108]. Furthermore, a follow-up 10-day in vivo study in mice confirmed that the AgNP-coated catheter was nontoxic [104]. Similarly, a clinical pilot study investigating the prevention of catheter-associated ventriculitis (CAV) found no incidence of $\mathrm{CAV}$, and all cerebrospinal fluid cultures were negative in the 19 patients that received a AgNPcoated catheter [109]. On the contrary, in the control group of 20 patients, 5 were positive for CAV [109].

5.4. Dentistry. AgNPs have also been applied to dental instruments and bandages. Akhavan et al. demonstrated that incorporating AgNPs into orthodontic adhesives could increase or maintain the shear bond strength of an orthodontic adhesive while simultaneously increasing its resistance to bacteria [110]. A recent study by Chladek et al. found that incorporating AgNPs into dental composites could reduce the microbial colonization of lining materials, enhancing the antifungal efficiency [111]. Similarly, AgNPs incorporated into endodontic fillings displayed an increased antibacterial effect against Streptococcus milleri, S. aureus, and E. faecalis [112].

5.5. Orthopedic and Orthodontic Implants and Fixations. Implant associated and joint replacement bacterial infections are high at $1.0-4.0 \%$ and are one of the most serious complications in orthopedic surgery because they are extremely difficult to treat and result in increased morbidity and significantly worse outcomes [31, 32, 41, 42]. Thus, AgNPs have been incorporated into plain poly(methyl methacrylate) bone cement, used for the secure attachment of joint prostheses hip and knee replacement surgery, as a way to reduce bacterial resistance [31, 41]. Similarly, our lab investigated incorporating AgNPs into PLGA grafts as a potential for implant and fixation material in orthopedic and orthodontic surgery [32, 42]. All studies reported markedly increased antibacterial activity without significant toxicity [31, 32, 41, 42]. Additionally, our results indicated that AgNP/PLGA coating is a practical process that is nontoxic, easy to operate, and free of AgNP aggregation (Figures 1 and 2) [32, 76], suggesting that AgNP/PLGA-coated implants have excellent clinical potential for use in orthopedics and orthodontics.

5.6. Other Applications. AgNPs are also available in many commercial products such as water filters and purification systems, deodorants, soaps, socks, food preservation, and room sprays [34-36,57,77], which contributes to the increasing market of AgNPs.

\section{Future Outlook}

The use of AgNPs is already established for many commercial applications and certain medical applications, such as wound dressings, while many new potential applications are being heavily investigated. AgNPs possess great potential due to their antibacterial, antifungal, antiviral, and anti-inflammatory properties while our recent research has revealed novel osteoinductive properties as well. However, the mechanisms and biological interactions behind these properties are not fully understood. For example, the relationship between the size and shape of AgNPs and their biological properties and toxicity is not clearly revealed and thus requires further investigation as AgNP use continues to increase. Therefore, there is a pressing need to fully elucidate the mechanisms concerning the efficacy and toxicity of AgNPs before widespread medical application can occur.

\section{Conflict of Interests}

Kang Ting, Chia Soo, and Zhong Zheng are inventors of silver nanoparticle-related patents filed from UCLA.

\section{Acknowledgments}

The authors would like to thank Nadia Barakat from the University of California, Berkeley, for assistance in the preparation of this paper. This research is supported by the National Center for Advancing Translational Sciences UCLA CTSI Grant UL1TR000124.

\section{References}

[1] A. D. Russell and W. B. Hugo, "7 Antimicrobial activity and action of silver," in Progress in Medicinal Chemistry, pp. 351-370, 1994.

[2] B. S. Atiyeh, M. Costagliola, S. N. Hayek, and S. A. Dibo, "Effect of silver on burn wound infection control and healing: review of the literature," Burns, vol. 33, no. 2, pp. 139-148, 2007.

[3] K. Van De Voorde, T. Nijsten, K. Schelfhout, G. Moorkens, and J. Lambert, "Long term use of silver containing nose-drops resulting in systemic argyria," Acta Clinica Belgica, vol. 60, no. 1, pp. 33-35, 2005. 
[4] H. Vik, K. J. Andersen, K. Julshamn, and K. Todnem, "Neuropathy caused by silver absorption from arthroplasty cement," The Lancet, vol. 1, no. 8433, p. 872, 1985.

[5] E. Sudmann, H. Vik, M. Rait et al., "Systemic and local silver accumulation after total hip replacement using silverimpregnated bone cement," Medical Progress through Technology, vol. 20, no. 3-4, pp. 179-184, 1994.

[6] Y. Sun, B. Mayers, and Y. Xia, “Transformation of silver nanospheres into nanobelts and triangular nanoplates through a thermal process," Nano Letters, vol. 3, no. 5, pp. 675-679, 2003.

[7] A. Panáček, L. Kvítek, R. Prucek et al., "Silver colloid nanoparticles: synthesis, characterization, and their antibacterial activity," The Journal of Physical Chemistry B, vol. 110, no. 33, pp. 1624816253, 2006.

[8] D. Williams, "The relationship between biomaterials and nanotechnology," Biomaterials, vol. 29, no. 12, pp. 1737-1738, 2008.

[9] K. M. M. Abou El-Nour, A. A. Eftaiha, A. Al-Warthan, and R. A. A. Ammar, "Synthesis and applications of silver nanoparticles," Arabian Journal of Chemistry, vol. 3, no. 3, pp. 135-140, 2010.

[10] L. Ge, Q. Li, M. Wang, J. Ouyang, X. Li, and M. M. Q. Xing, "Nanosilver particles in medical applications: synthesis, performance, and toxicity," International Journal of Nanomedicine, vol. 9, no. 1, pp. 2399-2407, 2014.

[11] R. Sato-Berŕu, R. Redón, A. Vázquez-Olmos, and J. M. Saniger, "Silver nanoparticles synthesized by direct photoreduction of metal salts. Application in surface-enhanced Raman spectroscopy," Journal of Raman Spectroscopy, vol. 40, no. 4, pp. 376380, 2009.

[12] N. Vigneshwaran, R. P. Nachane, R. H. Balasubramanya, and P. V. Varadarajan, "A novel one-pot "green" synthesis of stable silver nanoparticles using soluble starch," Carbohydrate Research, vol. 341, no. 12, pp. 2012-2018, 2006.

[13] G.-N. Xu, X.-L. Qiao, X.-L. Qiu, and J.-G. Chen, "Preparation and characterization of stable monodisperse silver nanoparticles via photoreduction," Colloids and Surfaces A: Physicochemical and Engineering Aspects, vol. 320, no. 1-3, pp. 222-226, 2008.

[14] A. J. Kora, R. Manjusha, and J. Arunachalam, "Superior bactericidal activity of SDS capped silver nanoparticles: synthesis and characterization," Materials Science and Engineering C, vol. 29, no. 7, pp. 2104-2109, 2009.

[15] D. Mandal, M. E. Bolander, D. Mukhopadhyay, G. Sarkar, and P. Mukherjee, "The use of microorganisms for the formation of metal nanoparticles and their application," Applied Microbiology and Biotechnology, vol. 69, no. 5, pp. 485-492, 2006.

[16] L. Sintubin, W. de Windt, J. Dick et al., "Lactic acid bacteria as reducing and capping agent for the fast and efficient production of silver nanoparticles," Applied Microbiology and Biotechnology, vol. 84, no. 4, pp. 741-749, 2009.

[17] D. S. Balaji, S. Basavaraja, R. Deshpande, D. B. Mahesh, B. K. Prabhakar, and A. Venkataraman, "Extracellular biosynthesis of functionalized silver nanoparticles by strains of Cladosporium cladosporioides fungus," Colloids and Surfaces B: Biointerfaces, vol. 68, no. 1, pp. 88-92, 2009.

[18] M. Solgi, "Evaluation of plant-mediated Silver nanoparticles synthesis and its application in postharvest physiology of cut Flowers," Physiology and Molecular Biology of Plants, vol. 20, no. 3, pp. 279-285, 2014.

[19] F. M. Reicha, A. Sarhan, M. I. Abdel-Hamid, and I. M. ElSherbiny, "Preparation of silver nanoparticles in the presence of chitosan by electrochemical method," Carbohydrate Polymers, vol. 89, no. 1, pp. 236-244, 2012.
[20] V. Thomas, M. M. Yallapu, B. Sreedhar, and S. K. Bajpai, "Fabrication, characterization of chitosan/nanosilver film and its potential antibacterial application," Journal of Biomaterials Science, Polymer Edition, vol. 20, no. 14, pp. 2129-2144, 2009.

[21] K. Shameli, M. B. Ahmad, W. M. Z. W. Yunus et al., "Green synthesis of silver/montmorillonite/chitosan bionanocomposites using the UV irradiation method and evaluation of antibacterial activity," International Journal of Nanomedicine, vol. 5, no. 1, pp. 875-887, 2010.

[22] H. Huang and Y. Yang, "Preparation of silver nanoparticles in inorganic clay suspensions," Composites Science and Technology, vol. 68, no. 14, pp. 2948-2953, 2008.

[23] H. Mighri, H. Hajlaoui, A. Akrout, H. Najjaa, and M. Neffati, "Antimicrobial and antioxidant activities of Artemisia herbaalba essential oil cultivated in Tunisian arid zone," Comptes Rendus Chimie, vol. 13, no. 3, pp. 380-386, 2010.

[24] V. Vilas, D. Philip, and J. Mathew, "Catalytically and biologically active silver nanoparticles synthesized using essential oil," Spectrochimica Acta Part A: Molecular and Biomolecular Spectroscopy, vol. 132, pp. 743-750, 2014.

[25] A. R. Vilchis-Nestor, V. Sánchez-Mendieta, M. A. CamachoLópez, R. M. Gómez-Espinosa, M. A. Camacho-López, and J. A. Arenas-Alatorre, "Solventless synthesis and optical properties of $\mathrm{Au}$ and $\mathrm{Ag}$ nanoparticles using Camellia sinensis extract," Materials Letters, vol. 62, no. 17-18, pp. 3103-3105, 2008.

[26] T. Calandra and J. Cohen, "The International Sepsis Forum Consensus Conference on definitions of infection in the intensive care unit," Critical Care Medicine, vol. 33, no. 7, pp. 15381548, 2005.

[27] V. Amendola and M. Meneghetti, "Laser ablation synthesis in solution and size manipulation of noble metal nanoparticles," Physical Chemistry Chemical Physics, vol. 11, no. 20, pp. 38053821, 2009.

[28] T. Tsuji, N. Watanabe, and M. Tsuji, "Laser induced morphology change of silver colloids: formation of nano-size wires," Applied Surface Science, vol. 211, no. 1-4, pp. 189-193, 2003.

[29] D.-C. Tien, K.-H. Tseng, C.-Y. Liao, and T.-T. Tsung, “Colloidal silver fabrication using the spark discharge system and its antimicrobial effect on Staphylococcus aureus," Medical Engineering and Physics, vol. 30, no. 8, pp. 948-952, 2008.

[30] K. Chaloupka, Y. Malam, and A. M. Seifalian, "Nanosilver as a new generation of nanoproduct in biomedical applications," Trends in Biotechnology, vol. 28, no. 11, pp. 580-588, 2010.

[31] V. Alt, T. Bechert, P. Steinrücke et al., "An in vitro assessment of the antibacterial properties and cytotoxicity of nanoparticulate silver bone cement," Biomaterials, vol. 25, no. 18, pp. 4383-4391, 2004.

[32] Z. Zheng, W. Yin, J. N. Zara et al., "The use of BMP-2 couplednanosilver-PLGA composite grafts to induce bone repair in grossly infected segmental defects," Biomaterials, vol. 31, no. 35, pp. 9293-9300, 2010.

[33] G. Zhang, Y. Liu, X. Gao, and Y. Chen, "Synthesis of silver nanoparticles and antibacterial property of silk fabrics treated by silver nanoparticles," Nanoscale Research Letters, vol. 9, no. 1, p. 216, 2014.

[34] Q. Chaudhry, M. Scotter, J. Blackburn et al., "Applications and implications of nanotechnologies for the food sector," Food Additives and Contaminants A: Chemistry, Analysis, Control, Exposure and Risk Assessment, vol. 25, no. 3, pp. 241-258, 2008.

[35] T. M. Benn and P. Westerhoff, "Nanoparticle silver released into water from commercially available sock fabrics," Environmental Science and Technology, vol. 42, no. 11, pp. 4133-4139, 2008. 
[36] R. Manjumeena, D. Duraibabu, J. Sudha, and P. T. Kalaichelvan, "Biogenic nanosilver incorporated reverse osmosis membrane for antibacterial and antifungal activities against selected pathogenic strains: an enhanced eco-friendly water disinfection approach," Journal of Environmental Science and Health-Part A Toxic/Hazardous Substances and Environmental Engineering, vol. 49, no. 10, pp. 1125-1133, 2014.

[37] P. L. Nadworny, J. Wang, E. E. Tredget, and R. E. Burrell, "Antiinflammatory activity of nanocrystalline silver in a porcine contact dermatitis model," Nanomedicine: Nanotechnology, Biology, and Medicine, vol. 4, no. 3, pp. 241-251, 2008.

[38] Y. Huang, X. Li, Z. Liao et al., "A randomized comparative trial between Acticoat and SD-Ag in the treatment of residual burn wounds, including safety analysis," Burns, vol. 33, no. 2, pp. 161166, 2007.

[39] J. Pulit, M. Banach, R. Szczygłowska, and M. Bryk, "Nanosilver against fungi. Silver nanoparticles as an effective biocidal factor," Acta Biochimica Polonica, vol. 60, no. 4, pp. 795-798, 2013.

[40] C.-N. Lok, C.-M. Ho, R. Chen et al., "Silver nanoparticles: partial oxidation and antibacterial activities," Journal of Biological Inorganic Chemistry, vol. 12, no. 4, pp. 527-534, 2007.

[41] H. van de Belt, D. Neut, W. Schenk, J. R. van Horn, H. C. van der Mei, and H. J. Busscher, "Infection of orthopedic implants and the use of antibiotic-loaded bone cements," Acta Orthopaedica Scandinavica, vol. 72, no. 6, pp. 557-571, 2001.

[42] Y. Liu, Z. Zheng, J. N. Zara et al., "The antimicrobial and osteoinductive properties of silver nanoparticle/poly (dl-lacticco-glycolic acid)-coated stainless steel," Biomaterials, vol. 33, no. 34, pp. 8745-8756, 2012.

[43] L. G. Ovington, "The truth about silver," Ostomy Wound Management, vol. 50, no. 9, supplement, pp. 1s-10s, 2004.

[44] S. Silver, L. T. Phung, and G. Silver, "Silver as biocides in burn and wound dressings and bacterial resistance to silver compounds," Journal of Industrial Microbiology and Biotechnology, vol. 33, no. 7, pp. 627-634, 2006.

[45] P. Sanpui, A. Murugadoss, P. V. D. Prasad, S. S. Ghosh, and A. Chattopadhyay, "The antibacterial properties of a novel chitosan-Ag-nanoparticle composite," International Journal of Food Microbiology, vol. 124, no. 2, pp. 142-146, 2008.

[46] J. R. Morones, J. L. Elechiguerra, A. Camacho et al., "The bactericidal effect of silver nanoparticles," Nanotechnology, vol. 16, no. 10, pp. 2346-2353, 2005.

[47] S. Shrivastava, T. Bera, S. K. Singh, G. Singh, P. Ramachandrarao, and D. Dash, "Characterization of antiplatelet properties of silver nanoparticles," ACS Nano, vol. 3, no. 6, pp. 1357-1364, 2009.

[48] A. Masse, A. Bruno, M. Bosetti, A. Biasibetti, M. Cannas, and P. Gallinaro, "Prevention of pin track infection in external fixation with silver coated pins: clinical and microbiological results," Journal of Biomedical Materials Research, vol. 53, no. 5, pp. 600604, 2000.

[49] G. A. Martinez-Castanon, N. Niño-Martínez, F. MartínezGutierrez, J. R. Martínez-Mendoza, and F. Ruiz, "Synthesis and antibacterial activity of silver nanoparticles with different sizes," Journal of Nanoparticle Research, vol. 10, no. 8, pp. 1343-1348, 2008.

[50] G. A. Sotiriou and S. E. Pratsinis, "Antibacterial activity of nanosilver ions and particles," Environmental Science and Technology, vol. 44, no. 14, pp. 5649-5654, 2010.

[51] O. Choi, K. K. Deng, N.-J. Kim, L. Ross Jr., R. Y. Surampalli, and $\mathrm{Z}$. Hu, "The inhibitory effects of silver nanoparticles, silver ions, and silver chloride colloids on microbial growth," Water Research, vol. 42, no. 12, pp. 3066-3074, 2008.

[52] C.-N. Lok, C.-M. Ho, R. Chen et al., "Proteomic analysis of the mode of antibacterial action of silver nanoparticles," Journal of Proteome Research, vol. 5, no. 4, pp. 916-924, 2006.

[53] J. S. Kim, E. Kuk, K. N. Yu et al., "Antimicrobial effects of silver nanoparticles," Nanomedicine: Nanotechnology, Biology, and Medicine, vol. 3, no. 1, pp. 95-101, 2007.

[54] W. Lee, K. J. Kim, and D. G. Lee, "A novel mechanism for the antibacterial effect of silver nanoparticles on Escherichia coli," Biometals, vol. 27, no. 6, pp. 1191-1201, 2014.

[55] M. Yamanaka, K. Hara, and J. Kudo, "Bactericidal actions of a silver ion solution on Escherichia coli, studied by energyfiltering transmission electron microscopy and proteomic analysis," Applied and Environmental Microbiology, vol. 71, no. 11, pp. 7589-7593, 2005.

[56] K. J. Woo, C. K. Hye, W. K. Ki, S. Shin, H. K. So, and H. P. Yong, "Antibacterial activity and mechanism of action of the silver ion in Staphylococcus aureus and Escherichia coli," Applied and Environmental Microbiology, vol. 74, no. 7, pp. 2171-2178, 2008.

[57] W. Yang, C. Shen, Q. Ji et al., "Food storage material silver nanoparticles interfere with DNA replication fidelity and bind with DNA," Nanotechnology, vol. 20, no. 8, Article ID 085102, 2009.

[58] S. H. Jeong, S. Y. Yeo, and S. C. Yi, “The effect of filler particle size on the antibacterial properties of compounded polymer/silver fibers," Journal of Materials Science, vol. 40, no. 20, pp. 54075411, 2005.

[59] G. A. Martinez-Castanon, N. Niño-Martínez, F. MartínezGutierrez, J. R. Martínez-Mendoza, and F. Ruiz, "Synthesis and antibacterial activity of silver nanoparticles with different sizes," Journal of Nanoparticle Research, vol. 10, no. 8, pp. 1343-1348, 2008.

[60] F. Martinez-Gutierrez, P. L. Olive, A. Banuelos et al., "Synthesis, characterization, and evaluation of antimicrobial and cytotoxic effect of silver and titanium nanoparticles," Nanomedicine: Nanotechnology, Biology, and Medicine, vol. 6, no. 5, pp. 681-688, 2010.

[61] B. Sadeghi, F. S. Garmaroudi, M. Hashemi, H. R. Nezhad, A. Nasrollahi, and S. Ardalan, "Comparison of the anti-bacterial activity on the nanosilver shapes: nanoparticles, nanorods and nanoplates," Advanced Powder Technology, vol. 23, no. 1, pp. 2226, 2012.

[62] S. Gaikwad, A. Ingle, A. Gade et al., "Antiviral activity of mycosynthesized silver nanoparticles against herpes simplex virus and human parainfluenza virus type 3," International Journal of Nanomedicine, vol. 8, pp. 4303-4314, 2013.

[63] D. Baram-Pinto, S. Shukla, N. Perkas, A. Gedanken, and R. Sarid, "Inhibition of herpes simplex virus type 1 infection by silver nanoparticles capped with mercaptoethane sulfonate," Bioconjugate Chemistry, vol. 20, no. 8, pp. 1497-1502, 2009.

[64] L. Lu, R. W.-Y. Sun, R. Chen et al., "Silver nanoparticles inhibit hepatitis B virus replication," Antiviral Therapy, vol. 13, no. 2, pp. 253-262, 2008.

[65] H. H. Lara, N. V. Ayala-Nuñez, L. Ixtepan-Turrent, and C. Rodriguez-Padilla, "Mode of antiviral action of silver nanoparticles against HIV-1," Journal of Nanobiotechnology, vol. 8, article $1,2010$.

[66] R. L. Hu, S. R. Li, F. J. Kong, R. J. Hou, X. L. Guan, and F. Guo, "Inhibition effect of silver nanoparticles on herpes simplex virus 2," Genetics and Molecular Research, vol. 13, no. 3, pp. 7022-7028, 2014. 
[67] L. C. D’Avignon, J. R. Saffle, K. K. Chung, and L. C. Cancio, "Prevention and management of infections associated with burns in the combat casualty," Journal of Trauma-Injury, Infection and Critical Care, vol. 64, no. 3, pp. S277-S286, 2008.

[68] E. E. Tredget, H. A. Shankowsky, R. Rennie, R. E. Burrell, and S. Logsetty, "Pseudomonas infections in the thermally injured patient," Burns, vol. 30, no. 1, pp. 3-26, 2004.

[69] L. Martineau, S. C. Davis, H. T. Peng, and A. Hung, "Controlling methicillin resistant Staphyloccocus aureus and pseudomonas aeruginosa wound infections with a novel biomaterial," Journal of Investigative Surgery, vol. 20, no. 4, pp. 217-227, 2007.

[70] D. J. Barillo, "Topical antimicrobials in burn wound care: a recent history," Wounds, vol. 20, no. 7, pp. 192-198, 2008.

[71] W. G. Cioffi, "Conventional warfare: ballistic, blast, and burn injuries," in Textbook of Military Medicine: Part 1-Warfare, Weaponry, and the Casualty, pp. 349-377, 1989.

[72] C. R. Mackay, "Moving targets: cell migration inhibitors as new anti-inflammatory therapies," Nature Immunology, vol. 9, no. 9, pp. 988-998, 2008.

[73] S.-H. Shin and M.-K. Ye, "The effect of nano-silver on allergic rhinitis model in mice," Clinical and Experimental Otorhinolaryngology, vol. 5, no. 4, pp. 222-227, 2012.

[74] K. K. Y. Wong, S. O. F. Cheung, L. Huang et al., "Further evidence of the anti-inflammatory effects of silver nanoparticles," ChemMedChem, vol. 4, no. 7, pp. 1129-1135, 2009.

[75] S. Zhang, X. Liu, H. Wang, J. Peng, and K. K. Y. Wong, "Silver nanoparticle-coated suture effectively reduces inflammation and improves mechanical strength at intestinal anastomosis in mice," Journal of Pediatric Surgery, vol. 49, no. 4, pp. 606-613, 2014.

[76] Y. Liu, Z. Zheng, J. N. Zara et al., "The antimicrobial and osteoinductive properties of silver nanoparticle/poly (DLlactic-co-glycolic acid)-coated stainless steel," Biomaterials, vol. 33, no. 34, pp. 8745-8756, 2012.

[77] X. Chen and H. J. Schluesener, "Nanosilver: a nanoproduct in medical application," Toxicology Letters, vol. 176, no. 1, pp. 1-12, 2008.

[78] Y. S. Kim, J. S. Kim, H. S. Cho et al., "Twenty-eight-day oral toxicity, genotoxicity, and gender-related tissue distribution of silver nanoparticles in Sprague-Dawley rats," Inhalation Toxicology, vol. 20, no. 6, pp. 575-583, 2008.

[79] J. H. Ji, J. H. Jung, S. S. Kim et al., "Twenty-eight-day inhalation toxicity study of silver nanoparticles in Sprague-Dawley rats," Inhalation Toxicology, vol. 19, no. 10, pp. 857-871, 2007.

[80] P. Maneewattanapinyo, W. Banlunara, C. Thammacharoen, S. Ekgasit, and T. Kaewamatawong, "An evaluation of acute toxicity of colloidal silver nanoparticles," Journal of Veterinary Medical Science, vol. 73, no. 11, pp. 1417-1423, 2011.

[81] J. H. Sung, J. H. Ji, J. D. Park et al., "Subchronic inhalation toxicity of silver nanoparticles," Toxicological Sciences, vol. 108, no. 2, pp. 452-461, 2009.

[82] J. Tang, L. Xiong, S. Wang et al., "Influence of silver nanoparticles on neurons and blood-brain barrier via subcutaneous injection in rats," Applied Surface Science, vol. 255, no. 2, pp. 502-504, 2008

[83] R. J. Vandebriel, E. C. M. Tonk, L. J. de la Fonteyne-Blankestijn et al., "Immunotoxicity of silver nanoparticles in an intravenous 28-day repeated-dose toxicity study in rats," Acta Veterinaria Scandinavica, vol. 11, article 21, 2014.

[84] W. H. de Jong, L. T. M. van der ven, A. Sleijffers et al., "Systemic and immunotoxicity of silver nanoparticles in an intravenous
28 days repeated dose toxicity study in rats," Biomaterials, vol. 34, no. 33, pp. 8333-8343, 2013.

[85] K. J. Lee, P. D. Nallathamby, L. M. Browning, C. J. Osgood, and $\mathrm{X}$.-H. Nancy Xu, "In vivo imaging of transport and biocompatibility of single silver nanoparticles in early development of zebrafish embryos," ACS Nano, vol. 1, no. 2, pp. 133-143, 2007.

[86] P. V. AshaRani, G. L. K. Mun, M. P. Hande, and S. Valiyaveettil, "Cytotoxicity and genotoxicity of silver nanoparticles in human cells," ACS Nano, vol. 3, no. 2, pp. 279-290, 2009.

[87] S.-H. Shin, M.-K. Ye, H.-S. Kim, and H.-S. Kang, "The effects of nano-silver on the proliferation and cytokine expression by peripheral blood mononuclear cells," International Immunopharmacology, vol. 7, no. 13, pp. 1813-1818, 2007.

[88] S. M. Hussain, A. K. Javorina, A. M. Schrand, H. M. H. M. Duhart, S. F. Ali, and J. J. Schlager, "The interaction of manganese nanoparticles with $\mathrm{PC}-12$ cells induces dopamine depletion," Toxicological Sciences, vol. 92, no. 2, pp. 456-463, 2006.

[89] S. M. Hussain, K. L. Hess, J. M. Gearhart, K. T. Geiss, and J. J. Schlager, "In vitro toxicity of nanoparticles in BRL 3A rat liver cells," Toxicology in Vitro, vol. 19, no. 7, pp. 975-983, 2005.

[90] Y. H. Hsin, C. F. Chen, S. Huang, T. S. Shih, P. S. Lai, and P. J. Chueh, "The apoptotic effect of nanosilver is mediated by a ROS- and JNK-dependent mechanism involving the mitochondrial pathway in NIH3T3 cells," Toxicology Letters, vol. 179, no. 3, pp. 130-139, 2008.

[91] S. Park, Y. K. Lee, M. Jung et al., "Cellular toxicity of various inhalable metal nanoparticles on human alveolar epithelial cells," Inhalation Toxicology, vol. 19, no. 1, pp. 59-65, 2007.

[92] D. McShan, P. C. Ray, and H. Yu, "Molecular toxicity mechanism of nanosilver," Journal of Food and Drug Analysis, vol. 22, no. 1, pp. 116-127, 2014.

[93] S. C. Sahu, J. Zheng, L. Graham et al., "Comparative cytotoxicity of nanosilver in human liver HepG2 and colon Caco2 cells in culture," Journal of Applied Toxicology, vol. 34, no. 11, pp. 11551166, 2014.

[94] C. Carlson, S. M. Hussein, A. M. Schrand et al., "Unique cellular interaction of silver nanoparticles: size-dependent generation of reactive oxygen species," Journal of Physical Chemistry B, vol. 112, no. 43, pp. 13608-13619, 2008.

[95] N. Kumar, G. R. Palmer, V. Shah, and V. K. Walker, "The effect of silver nanoparticles on seasonal change in arctic tundra bacterial and fungal assemblages," PLoS ONE, vol. 9, no. 6, Article ID e99953, 2014.

[96] C. Völker, T. Gräf, I. Schneider, M. Oetken, and J. Oehlmann, "Combined effects of silver nanoparticles and $17 \alpha$-ethinylestradiol on the freshwater mudsnail Potamopyrgus antipodarum," Environmental Science and Pollution Research, vol. 21, no. 18, pp. 10661-10670, 2014.

[97] J. Chen, C.-M. Han, X.-W. Lin, Z.-J. Tang, and S.-J. Su, "Effect of silver nanoparticle dressing on second degree burn wound," Zhonghua Wai Ke Za Zhi/Chinese Journal of Surgery, vol. 44, no. 1, pp. 50-52, 2006.

[98] S. Lu, W. Gao, and H. Y. Gu, "Construction, application and biosafety of silver nanocrystalline chitosan wound dressing," Burns, vol. 34, no. 5, pp. 623-628, 2008.

[99] R. Singh and D. Singh, "Chitin membranes containing silver nanoparticles for wound dressing application," International Wound Journal, vol. 11, no. 3, pp. 264-268, 2014.

[100] K. Madhumathi, P. T. S. Kumar, S. Abhilash et al., "Development of novel chitin/nanosilver composite scaffolds for wound 
dressing applications," Journal of Materials Science: Materials in Medicine, vol. 21, no. 2, pp. 807-813, 2010.

[101] G. L. Grunkemeier, R. Jin, and A. Starr, "Prosthetic heart valves: objective performance criteria versus randomized clinical trial," Annals of Thoracic Surgery, vol. 82, no. 3, pp. 776-780, 2006.

[102] M. Andara, A. Agarwal, D. Scholvin et al., "Hemocompatibility of diamondlike carbon-metal composite thin films," Diamond and Related Materials, vol. 15, no. 11-12, pp. 1941-1948, 2006.

[103] H. Ghanbari, H. Viatge, A. G. Kidane, G. Burriesci, M. Tavakoli, and A. M. Seifalian, "Polymeric heart valves: new materials, emerging hopes," Trends in Biotechnology, vol. 27, no. 6, pp. 359367, 2009.

[104] D. Roe, B. Karandikar, N. Bonn-Savage, B. Gibbins, and J.B. Roullet, "Antimicrobial surface functionalization of plastic catheters by silver nanoparticles," Journal of Antimicrobial Chemotherapy, vol. 61, no. 4, pp. 869-876, 2008.

[105] S.-H. Hsu, H.-J. Tseng, and Y.-C. Lin, “The biocompatibility and antibacterial properties of waterborne polyurethane-silver nanocomposites," Biomaterials, vol. 31, no. 26, pp. 6796-6808, 2010.

[106] A. de Mel, K. Chaloupka, Y. Malam, A. Darbyshire, B. Cousins, and A. M. Seifalian, "A silver nanocomposite biomaterial for blood-contacting implants," Journal of Biomedical Materials Research-Part A, vol. 100, no. 9, pp. 2348-2357, 2012.

[107] F. Paladini, M. Pollini, D. Deponti, A. di Giancamillo, G. Peretti, and A. Sannino, "Effect of silver nanocoatings on catheters for haemodialysis in terms of cell viability, proliferation, morphology and antibacterial activity," Journal of Materials Science: Materials in Medicine, vol. 24, no. 4, pp. 1105-1112, 2013.

[108] C.-W. Chou, S.-H. Hsu, and P.-H. Wang, "Biostability and biocompatibility of poly(ether)urethane containing gold or silver nanoparticles in a porcine model," Journal of Biomedical Materials Research Part A, vol. 84, no. 3, pp. 785-794, 2008.

[109] P. Lackner, R. Beer, G. Broessner et al., "Efficacy of silver nanoparticles-impregnated external ventricular drain catheters in patients with acute occlusive hydrocephalus," Neurocritical Care, vol. 8, no. 3, pp. 360-365, 2008.

[110] A. Akhavan, A. Sodagar, F. Mojtahedzadeh, and K. Sodagar, "Investigating the effect of incorporating nanosilver/nanohydroxyapatite particles on the shear bond strength of orthodontic adhesives," Acta Odontologica Scandinavica, vol. 71, no. 5, pp. 1038-1042, 2013.

[111] G. Chladek, J. Kasperski, I. Barszczewska-Rybarek, and J. Zmudzki, "Sorption, solubility, bond strength and hardness of denture soft lining incorporated with silver nanoparticles," International Journal of Molecular Sciences, vol. 14, no. 1, pp. 563-574, 2013.

[112] A. P. R. Magalhães, L. B. Santos, L. G. Lopes et al., "Nanosilver application in dental cements," ISRN Nanotechnology, vol. 2012, Article ID 365438, 6 pages, 2012. 

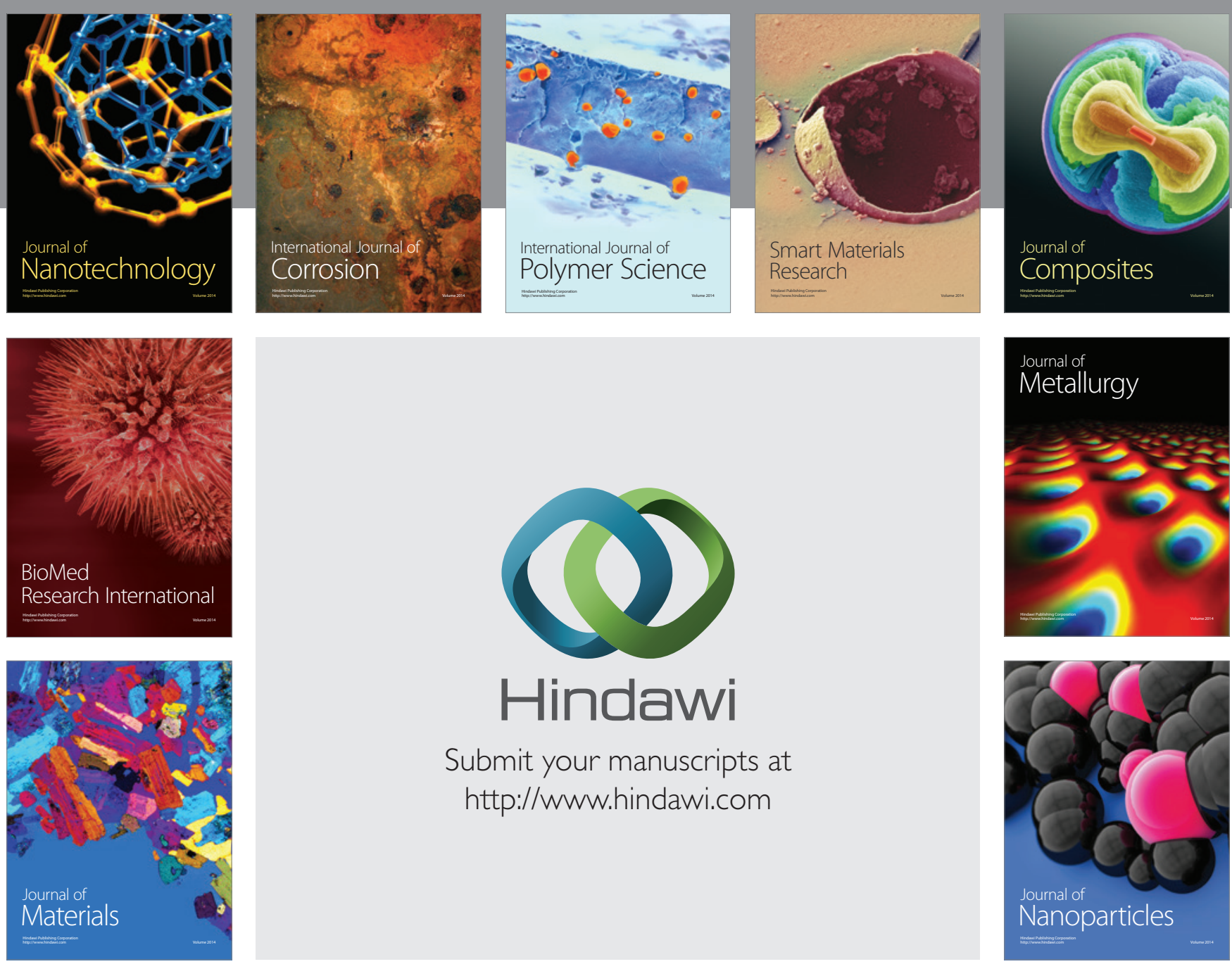

Submit your manuscripts at http://www.hindawi.com
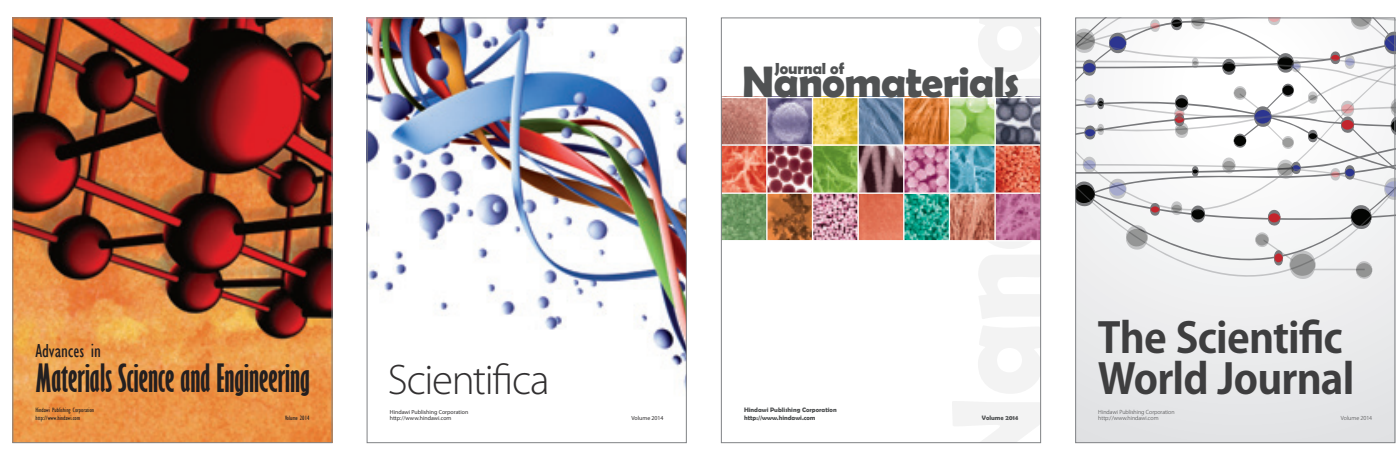

\section{The Scientific World Journal}
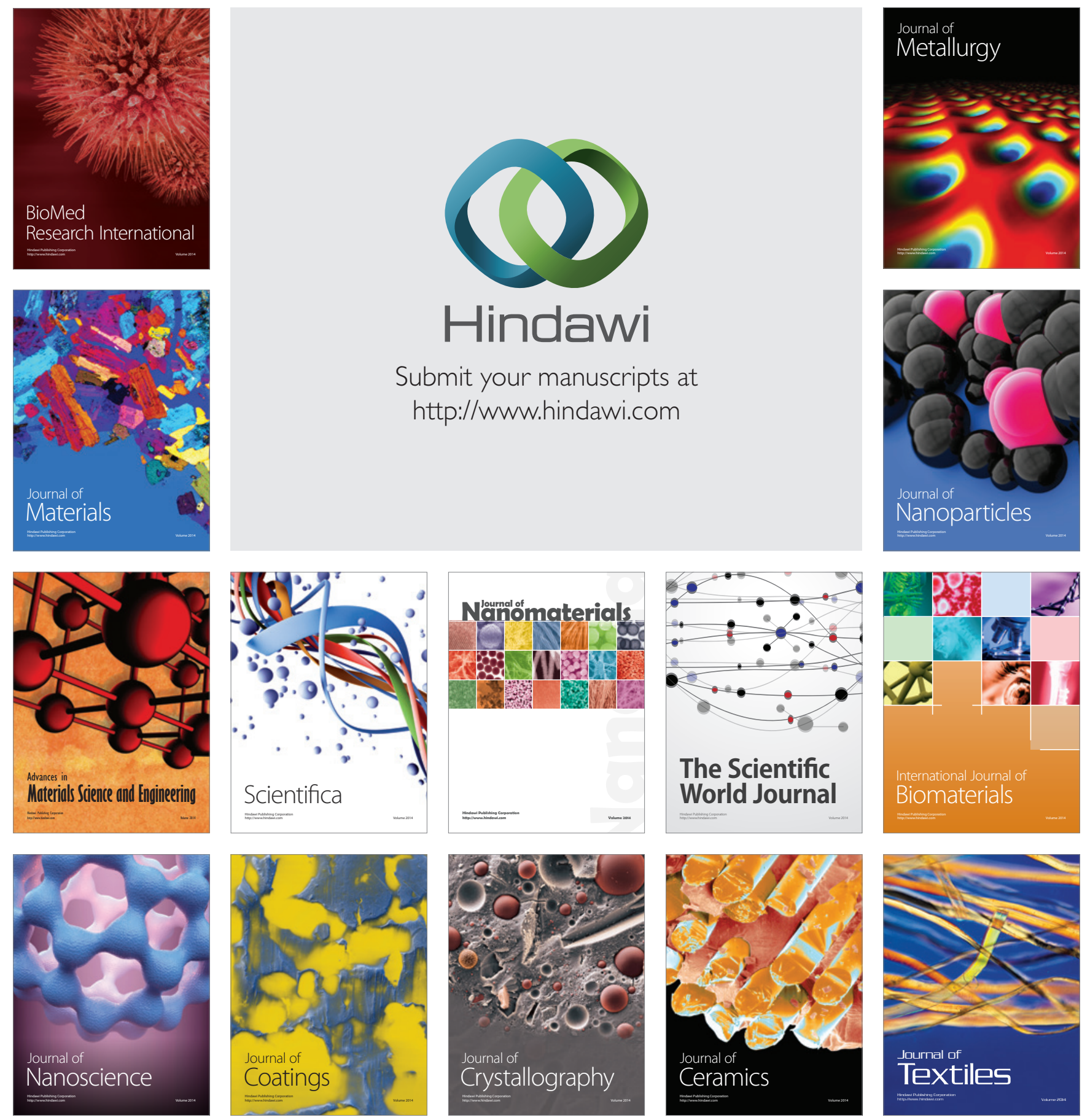